\section{Commentary: Transapical transapical mitral valve replacement: Here to stay or a gateway procedure?}

\author{
J. James Edelman, MBBS(Hons), PhD, ${ }^{a}$ \\ James Kauten, MD, ${ }^{\mathrm{b}}$ and Vinod H. Thourani, $\mathrm{MD}^{\mathrm{b}}$
}

In this issue of the Journal, Hong and Bapat ${ }^{1}$ provide an excellent, detailed "how-to-do-it" description of transapical (TA) mitral valve (MV) replacement (TMVR) of the Intrepid valve (Medtronic Corporation, Dublin, Ireland). The authors have extensive experience with this device and have previously authored one of the largest series of the Intrepid device reported to date. ${ }^{2}$ This contribution marks a gold standard in techniques for large-bore transapical MV replacement. ${ }^{2}$

There is an unmet clinical need for patients with severe secondary MV disease who are too high risk for surgery. Transcatheter treatment of the MV has lagged behind the overwhelming pace of transcatheter aortic valve replacement. This is largely due to the anatomical challenges of the MV-its noncircular, noncalcified annulus is a challenge for valve anchoring and it risks obstructing the left ventricular outflow tract by prosthesis displacement of the anterior MV leaflet. In the United States, the only approved transcatheter device is the MitraClip MV repair system (Abbott Vascular, Santa Clara, Calif). While this is currently approved for high-risk patients with primary

From ${ }^{\mathrm{a} D e p a r t m e n t}$ of Cardiothoracic Surgery, Fiona Stanley Hospital, Perth, Australia; and ${ }^{\mathrm{b}}$ Department of Cardiovascular Surgery, Marcus Heart Valve Center, Piedmont Heart Institute, Atlanta, Ga.

Disclosures: Dr Thourani is an advisor/has performed research for Abbott Vascular and Edwards Lifesciences and research for Medtronic Corporation. Dr Kauten has performed research for Medtronic Corporation. Dr Edelman reported no conflicts of interest.

The Journal policy requires editors and reviewers to disclose conflicts of interest and to decline handling or reviewing manuscripts for which they may have a conflict of interest. The editors and reviewers of this article have no conflicts of interest.

Received for publication March 9, 2020; revisions received March 9, 2020; accepted for publication March 11, 2020; available ahead of print April 4, 2020.

Address for reprints: Vinod H. Thourani, MD, Department of Cardiovascular Surgery, Piedmont Heart Institute, 95 Collier Rd, Suite 5015, Atlanta, GA 30308 (E-mail: vinod.thourani@piedmont.org).

JTCVS Techniques 2020;2:34-5

2666-2507

Copyright $(2020$ The Authors. Published by Elsevier Inc. on behalf of The American Association for Thoracic Surgery. This is an open access article under the CC BY-NCND license (http://creativecommons.org/licenses/by-nc-nd/4.0/).

https://doi.org/10.1016/j.xjtc.2020.03.025

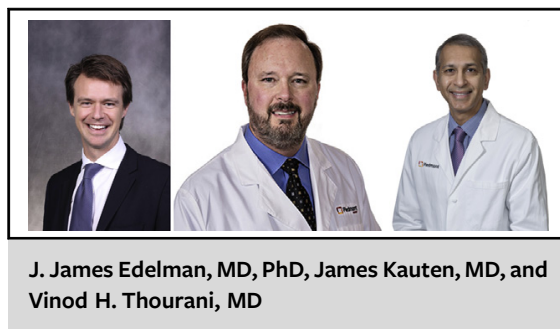

CENTRAL MESSAGE

Transcatheter mitral valve

replacement is rapidly evolving.

While the transapical route has

proven successful, it most likely is

the gateway to less-invasive

percutaneous transseptal

approaches.

mitral regurgitation (MR), the MitraClip has recently been approved for secondary MR in this patient cohort. The recently published COAPT trial was the first to demonstrate a mortality benefit of a transcatheter intervention in secondary MR. ${ }^{3}$ Its success was due in part to strict selection of patients most likely to benefit from an interventional procedure (maximum medical therapy in addition to "proportionate" rather than "disproportionate" MR) and minimization of surgical trauma (including avoidance of cardiopulmonary bypass). ${ }^{4}$ However, there remains a patient population that is not appropriate for the MitraClip secondary to the risk for residual MR or poor anatomical considerations. In these patients, transapical MV replacement may be a viable treatment modality. Such patients may have complex degenerative mitral leaflet pathology (including damaged leaflets not amenable to repair), healed infective endocarditis, diminutive posterior MV leaflet, small mitral valve area, mitral annular calcification, or rheumatic (or calcific) valve disease.

The 2 most commonly used TA MV replacement devices are the Intrepid and Tendyne (Abbott Vascular, Santa Clara, Calif) valve systems. In the United States, these 2 devices are in pivotal trials in the APOLLO (NCT03242642) and SUMMIT (Clinical Trial to Evaluate the Safety and Effectiveness of Using the Tendyne Mitral Valve System for the Treatment of Symptomatic Mitral Regurgitation; NCT03433274) trials, respectively. ${ }^{2,5}$ The APOLLO trial compares the Intrepid device with surgical MVR; the SUMMIT trial compares the Tendyne valve with MitraClip. 
Each have a substudy for enrollment in those with severe mitral annular calcification and at least moderate MR. The TIARA TMVR (Neovasc Inc, Richmond, British Columbia, Canada) early feasibility study has nearly finished recruitment (TIARA-I NCT02276547), whereas the CE-Mark TIARA-II trial (NCT03039855) is an international, single-arm trial currently recruiting patients.

Other devices are being trialed that are transseptal (and thus purely percutaneous). The SAPIEN M3 (Edwards Lifesciences, Irvine, Calif) places a balloon-expandable valve into a "dock" that encircles the chordae tendinae. This device has reported excellent outcomes in 10 patients. ${ }^{6}$ The EVOQUE (Edwards Lifesciences) system has replaced the CardiAQ and is recruiting patients in an early feasibility study (NCT02718001) that is underway. The Caisson TMVR system (LivaNova, London, United Kingdom) is being tested in the PRELUDE feasibility trial (Percutaneous Mitral Valve Replacement EvaLuation Utilizing IDE Early Feasibility Study; NCT02768402), which has completed recruitment but has not yet reported their results. The Highlife System has reported good technical results in a small number of patients with TA placement of the valve, and a trial is underway for transseptal placement (NCT04029363). ${ }^{7}$ Lastly, the Intrepid valve is being refitted to allow both TA and transseptal delivery.

In the pursuit of the optimal therapy for the treatment of secondary MR, technological advances are reaching beyond traditional surgical therapy. Transcatheter technology for this complex subset of patients is yet to have a distinct winner in the approach that may lead to improved patient outcomes. Although transcatheter MV repair is the simplest avenue today, residual MR (especially in younger or less sick patients) may limit the long-term use of this technology. In contrast, TA mitral valve replacement does eliminate the MR, but with the cost of a thoracotomy and associated complications, including impairment of the ejection fraction at 5 years as seen in patients undergoing TA transcatheter aortic valve replacement. ${ }^{8}$ As successful as the Intrepid and Tendyne valves are when placed by the transapical route, neither will be able to compete with an efficacious valve that can be placed percutaneously via the transseptal route.

\section{References}

1. Hong E, Bapat V. Transapical implantation of the Intrepid device: case planning and operative technique. J Thorac Cardiovasc Surg Tech. 2020;2 27-33.

2. Bapat V, Walton A, Duffy SJ, Reardon MJ, Kleiman NS, Spargias K, et al. Early experience with new transcatheter mitral valve replacement. J Am Coll Cardiol. 2018;71:12-21.

3. Stone GW, Lindenfeld J, Abraham WT, Kar S, Lim DS, Mishell JM, et al. Transcatheter mitral-valve repair in patients with heart failure. N Engl J Med. 2018;379: 2307-18.

4. Grayburn PA, Sannino A, Packer M. Proportionate and disproportionate functional mitral regurgitation. JACC Cardiovasc Imaging. 2019b;12:353-62.

5. Muller DWM, Farivar RS, Bae R, Grayburn PA, Stoler RC, Dahle G, et al. Transcatheter mitral valve replacement for patients with symptomatic mitral regurgitation: a global feasibility trial. J Am Coll Cardiol. 2017;69:381-91.

6. Webb JG, Murdoch DJ, Boone RH, Moss R, Attinger-Toller A, Blanke P, et al Percutaneous transcatheter mitral valve replacement. J Am Coll Cardiol. 2019; 73:1239-46.

7. Barbanti M, Piazza N, Mangiafico S, Buithieu J, Bleiziffer S, Ronsivalle G, et al Transcatheter mitral valve implantation using the HighLife system. JACC Cardiovasc Interv. 2017;10:1662-70.

8. Makkar RR, Thourani VH, Mack MJ, Kodali SK, Kapadia S, Webb JG, et al. Five-year outcomes of transcatheter or surgical aortic-valve replacement. N Engl J Med. 2020;382:799-809. 